\section{Integrative Medicine \\ International}

Integr Med Int 2014;1:65-66

\title{
Innovative Integrative Medicine
}

\author{
Gerhard Litscher
}

Research Unit for Complementary and Integrative Laser Medicine, Research Unit of Biomedical Engineering in Anesthesia and Intensive Care Medicine, and TCM Research Center Graz, Medical University of Graz, Graz, Austria

The terms 'medicine' and 'innovation' have been inseparable throughout medical history. Medical knowledge has continuously been expanding, and hand in hand with it went the development of technical solutions. From the beginning, interdisciplinarity also played a major role. The latest innovations in medicine over the recent years were and still are based on integrative medicine.

High-tech acupuncture is one of these crossover approaches and a very successful one at that [1]. Only last month, the 1st World Congress of High-Tech Acupuncture and Integrative Medicine (HTA\&IM-2014) took place in Nanjing, China (fig. 1) [2]. The first in a series of Annual World Congresses [3] served as an opportunity to present and discuss the state of the art of multidisciplinary approaches to the modernization of integrative medicine, especially traditional Chinese medicine and acupuncture. The future congresses will also be excellent opportunities to establish research networks and scientific communication on these interesting traditional and innovative medical topics.

As mentioned above, HTA\&IM-2014 was the first congress in a series of planned future conferences on the same topic. In 2015, the congress will take place in Hangzhou, China, from May 22 to 24. Several renowned top experts already agreed to participate, and we hope to establish this conference as an annual meeting point for researchers and practitioners. This is also a cordial invitation to the readers of Integrative Medicine International to become an active part of this event. Further information can be found at http://www.bitlifesciences. com/HTA\&IM2015 and http://www.litscher.info.

Integrative medicine is the combined use of conventional and complementary/alternative medical treatment methods, in which case the latter's safety and efficacy have to be proven scientifically. Because of its many benefits, integrative medicine deserves to be included in daily clinical practice [4]. 


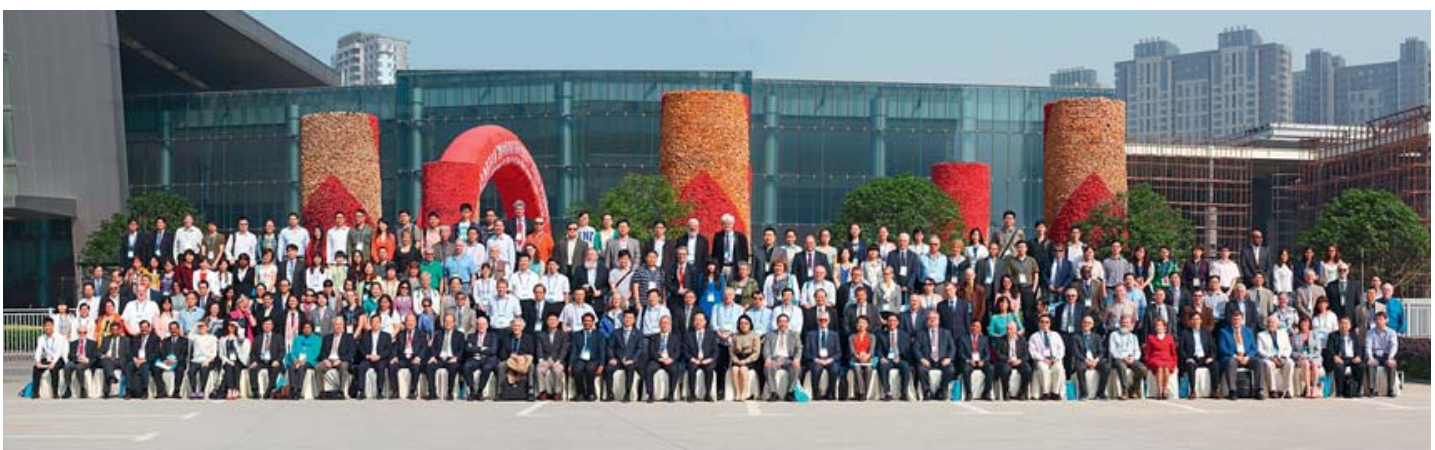

Fig. 1. Participants of the 1st World Congress of High-Tech Acupuncture and Integrative Medicine. Nanjing, May 16, 2014. Next congress: Hangzhou, China, May 22-24, 2015 (www.litscher.info).

There are many new evaluation methods and scientific devices for investigating integrative medicine. Apart from those mentioned by Pan and Zhou [4], new technical applications in manual therapy have to be mentioned here; further details on this topic can be found in an original paper published this year in this journal, too [5].

We therefore invite investigators and researchers to submit original research articles as well as review articles associated with integrative medicine to make these methods better known in the scientific community. We are particularly interested in articles dealing with Eastern/Oriental medicine and its possible contributions to Western medicine and vice versa. Contributors to the journal should be experts and scientists from all over the world. They are welcome to send their most recent research and describe current scientific medical trends.

This is a cordial invitation to all of you to submit high-level articles to our new journal.

\section{References}

1 Litscher G, Gao XY, Wang L, Zhu B: High-Tech Acupuncture and Integrative Laser Medicine, ed 1. Lengerich, Pabst Science Publishers, 2012.

2 1st World Congress of High-Tech Acupuncture and Integrative Medicine. http://www.bitlifesciences.com/ HTA\&IM2014 (accessed June 5, 2014).

3 2nd World Congress of High-Tech Acupuncture and Integrative Medicine. http://litscher.info (accessed June 5, 2014).

4 Pan WD, Zhou H: Inclusion of integrative medicine in clinical practice. Integr Med Int 2014;1:1-4.

5 Litscher D, Litscher G, Ofner M, Gaischek I, Malliga DE: Spectroscopic measurements in patients with completely ruptured anterior cruciate ligament before and after RegentK and physiotherapy. Integr Med Int 2014;1: 56-63. 